\title{
Dependence of the Cross Section of the Cut Layer on the Specific Cutting Resistance
}

\author{
Jana Petrů ${ }^{1, *}$, Tomáš Zlámal ${ }^{1}$, Lukáš Drábek ${ }^{1}$, Jiři Hajnyš ${ }^{1}$, and Dalibor Jurok ${ }^{1}$ \\ ${ }^{1}$ Faculty of Mechanical Engineering, VSB-Technical University of Ostrava, 17. listopadu 15/2172, \\ Ostrava, Czech Republic.
}

\begin{abstract}
This article deals with the study of the effect of cross section of the cut layer of material and its influence on the specific cutting resistance. Measurement and evaluation were carried out using two machined materials, according to the designation W.Nr. carbon steel 1.1191, which is a reference material for the steel grade and refractory nickel alloy 2.4856. For the purpose of the experiment, longitudinal turning technology with two interchangeable CNMG 120408 - SM and CNMX 1204A2 - SM cutting inserts was chosen. According to the recommended index insert values, two different types of cutting conditions were chosen for each material so that the cross section of the chip remained the same during machining. For each material, the cutting speed was constant and the feed rate and cutting depth were changed. The main goal of the experimental work was comparison of the specific cutting resistance in dependence on different cross section of the removed layer of material. On the basis of measuring of cutting forces by dynamometer Kistler the resulting cutting force was determined and the size of the specific cutting resistance was calculated.
\end{abstract}

Keywords: nickel alloy, machining, cutting tool, cutting force, cutting resistance

\section{Introduction}

Machining of the material is a very complex dynamic process in which the cutting tool acts as a tool for separating the chip material from the surface of the machined material. The mechanism of chip formation and the action of the cutting edge on the machined material causes a state of tension in the material. This process is accompanied by plastic and elastic deformations and force ratios. Examining these power ratios in the machining process gives us an over-view of the mechanical stress of the machine-tool-workpiece system. Knowledge of power ratios during machining is important for assessing material workability, durability and lifetime of cutting tools, and impact on the integrity of the machined surface [1].

The power ratios accompanying the cutting process can be decomposed into a chip force acting perpendicular to the tool face and the frictional force acting on the contact surface of the cut-off material. Both of these forces are part of the total cutting power. Cutting force is

* Corresponding author: jana.petru@vsb.cz

Reviewers: Marcin Kubiak, Tomáš Lack 
a time-varying and dynamic phenomenon. When machining, its instantaneous size changes, even when machined under constant cutting conditions. This variability is mainly due to the scattering of mechanical properties, the inhomogeneity of the machined material and the chip formation mechanism [2].

Measurement and evaluation of cutting forces during machining is of great importance today. Author Grossi, N. in his article Accurate and fast measurement of specific cutting force coefficients changing with spindle speeds deals with predictive cutting forces to simulate the dynamic effects of the milling process and optimize process parameters to reduce harmful vibrations. Cutting forces are conventionally modelled by assuming dependence on uneven chip thick-ness by specific coefficients. These coefficients vary significantly depending on spindle speed. The paper presents a method of efficiently identifying specific cutting force coefficients over the entire speed range [3].

Another article dedicated to cutting forces for turning published by Yao, C., Zhou, Z., Zhang, J., Wu, D., Tan, L., entitled: Experimental study on cutting force of face-turning Inconel718 with ceramic tools and carbide tools. The article deals with the process of face turning of the high temperature alloy of Inconel 718. During the process the cutting forces were monitored and empirical cutting models were subsequently determined. For tools, the main cutting force is positive in relation to feed rate and cutting depth [4].

Authors Turkes, E., Orak, S., Neseli, S., Sahin, M., Selvi, S. solve problematic of cutting forces in article Modelling of dynamic cutting force coefficients and chatter stability dependent on shear angle oscillation. For the productivity of high-speed lathes, it is important to reduce the occurrence of self-excited vibrations, known as vibration. If this fails and vibrations can cause a large dynamic load that damages the machine spindle, the cutting tool, the workpiece, or leaves poor surface quality. Cutting forces are directly proportional to the thickness of the chips removed from the surface [5].

Brinksmeier, E., Preuss, W., Riemer, O., Rentsch, R. in Cutting forces, tool wear and surface finish in high speed diamond machining deal with cutting and tool wear and surface quality in copper, brass, aluminium and nickel. The experiment was performed on faceturning with a constant material removal rate [6].

The article investigates the effects of cutting parameters on the integrity of the surface during machining.

\section{Cutting process and cutting forces}

The machining process affects the machined material and material of the cutting tool. The choice of tool depends on the required resistance to wear, toughness, strength, heat shock resistance, high heat hardness, chemical stability at high temperatures and tool stress. Also important is the choice of cutting geometry that affects the tool's durability and the accuracy and quality of the machined surface.

The choice of the cutting tool depends mainly on the type of machined material, production technology, cutting fluency and machining machine. The most used materials for machining are sintered carbides, cutting ceramics, high-speed steels, diamond and cubic boron nitride. Each of these materials is suitable for other machining technology and other machined materials [7].

Another important feature is tool geometry. This is due to a type of operation such as roughing or finishing. Machined material also plays an important role. Appropriate geometry of the tool is chosen with respect to the strength of the cutting wedge. Geometry must also be chosen with a view to ensuring a smooth course of machining without vibrations and with vibrations [8].

By intrusion the cutting tool into the material, the stresses that are leading to the plastic and elastic deformation of the machined material are concentrated before and under the tool 
cutting edge. During the insertion of the cutting wedge into the material, the shear stress increases, until the plastic deformation occurs in front of the tool edge in the sliding plane in the yield plane.

The main factors that affect chip formation are the cutting depth and tool feed, the tool setting angle, and the radius of the tip. The goal of choosing the right tool geometry is to achieve arched or spiral chips that are of a suitable length and can easily be removed from the cut. The width and shape of the chips affects the depth of the cut and, along with the angle of adjustment, determines the cutting edge length. In the case of an angle of $90^{\circ}$, it is equal to the cutting depth. Chip formation affects the setting angle along with the radius of the tip of the cutting insert. The smaller the setting angle, the smaller the chip thickness and the larger the width. The depth of cut affects not only the radius of the tip, but also chip formation and chips removal from the cutting point. In the case of a small cutting depth and a large tip radius, the cutting edge is formed primarily by a rounded toe, which supports the formation of spiral chips [8-11].

Cutting machining conditions mainly concern the cutting speed $v_{c}$, the feed rate $f$ and the thickness of the drawn layer. Cutting speed is the speed that moves the workpiece circumference in the direction opposite the cutting tool blade and has a great effect on the life of the cutting tool. When the speed is too low, there is an increase in the cutting edge and it becomes dull, the surface roughness of the part is poor. On the contrary, too high a speed causes wear on the tool back and poor quality of the work surface.

In case the speed is too low, long and continuous chips occur. When the speed is too high, there is high power consumption and chipping and chipping.

The mechanism of chip formation causes a state of tension in the material. Examining power ratios in the machining process allows you to get an overview of the mechanical stress of the machine tool-workpiece, stiffness, strength and stability of the cutting process.

The force ratios in the cutting process can be decomposed into a chip force acting perpendicular to the tool face $F_{n}$ and the frictional force $F_{t}$ acting on the contact surface of the tool with the cut-off layer of material. These components are consequently included in the resulting cutting force $F$. By effecting the resulting cutting force, the material creates a stress state that causes a deformation cutting resistance $R$. This cutting resistance must cut the cutting force when removing the material. The total force applied by the tool on the workpiece is called the cutting force $F$. The cutting resistance $R$ is the force of the workpiece on the tool $[12,13]$.

Machining produces large pressure and shear forces that act in different directions, so the cutting force breaks into components to determine the size and direction of the resulting force effect. The cutting tangential component of the $F c$ force is of greatest importance, which forms the basis for determining the limiting conditions in the selection of the cutting parameters.

\section{Experimental tests}

In the experiment the problem of the cross-sectional dependence of the extracted layer of material and its effect on the specific cutting resistance is solved. The experiment was performed on a CNC lathe. A chassis dynamometer was attached to a special holder on the turret's head and a tool holder into which the individual cutting inserts were clamped. Using an optical cable connected to the chassis dynamometer unit, the measured values were fed to the amplifier. The values were transposed as a millivolt voltage to the converter. The results were processed using a PC assembly and software developed for this purpose.

First, it was necessary to design two chips cross sections for each of the plates to have the closest values. The cross-section of the chips was determined using the formula for 
calculating the cross-section of the chip, the nominal thickness $h_{D}$ at two different feeds $f$ and the nominal width of the $b_{D}$ chip at two different depths of cut $a_{p}$.

Table 1. Cutting conditions of experimental tests

\begin{tabular}{|c|c|c|c|c|c|}
\hline Mat. & CNMG 120408-SM & $a_{p}=1 \mathrm{~mm}$ & $f=0.4 \mathrm{~mm}$ & $v_{c}=180 \mathrm{~m} / \mathrm{min}$ & Test 1 \\
\cline { 2 - 6 } & CNMG 120408-SM & $a_{p}=2 \mathrm{~mm}$ & $f=0.2 \mathrm{~mm}$ & $v_{c}=180 \mathrm{~m} / \mathrm{min}$ & Test 2 \\
\cline { 2 - 6 } & CNMG 1204A2 -SM & $a_{p}=1 \mathrm{~mm}$ & $f=0.4 \mathrm{~mm}$ & $v_{c}=180 \mathrm{~m} / \mathrm{min}$ & Test 3 \\
\cline { 2 - 6 } & CNMG 1204A2 -SM & $a_{p}=2 \mathrm{~mm}$ & $f=0.2 \mathrm{~mm}$ & $v_{c}=180 \mathrm{~m} / \mathrm{min}$ & Test 4 \\
\hline $\begin{array}{c}\text { Mat. } \\
2.4856\end{array}$ & CNMG 120408-SM & $a_{p}=1 \mathrm{~mm}$ & $f=0.3 \mathrm{~mm}$ & $v_{c}=40 \mathrm{~m} / \mathrm{min}$ & Test 1 \\
\cline { 2 - 6 } & CNMG 120408-SM & $a_{p}=2 \mathrm{~mm}$ & $f=0.15 \mathrm{~mm}$ & $v_{c}=40 \mathrm{~m} / \mathrm{min}$ & Test 2 \\
\cline { 2 - 6 } & CNMG 1204A2 -SM & $a_{p}=1 \mathrm{~mm}$ & $f=0.3 \mathrm{~mm}$ & $v_{c}=40 \mathrm{~m} / \mathrm{min}$ & Test 3 \\
\cline { 2 - 6 } & CNMG 1204A2 $-\mathrm{SM}$ & $a_{p}=2 \mathrm{~mm}$ & $f=0.15 \mathrm{~mm}$ & $v_{c}=40 \mathrm{~m} / \mathrm{min}$ & Test 4 \\
\hline
\end{tabular}

During the lathe, the measured data containing the $F_{x}\left(F_{p}\right), F_{y}\left(F_{c}\right)$, and $F_{z}\left(F_{f}\right)$ values were measured. Assuming that the magnitude of the cutting force during machining changes over time, the limiting element becomes a stretch reaching maximum values. These values correspond to the maximum value of the cutting resistance of the workpiece to the cutting tool wedge. High cutting forces mean high performance, which is limited. There is a large deformation of cutting tools and workpieces, resulting in unwanted vibration and wear of the tool.

\section{Experiment results}

Figure 1 shows a machining of the material 1.1191, cutting speed $v_{c}=180 \mathrm{~m} / \mathrm{min}$, feed $f=0.4 \mathrm{~mm}$ and cutting depth $a_{p}=1 \mathrm{~mm}$. On the left, a figure is displayed without filtered values and on the right using the Low Pass filter. The high frequency of oscillation was eliminated on the filtered chart.

Measurement and subsequent evaluation of power ratios during machining was performed by means of four tests for both materials. An example of output data is shown in Table 2, where the $F_{c}, F_{f}, F_{p} F_{v}$ measurement for steel 1.1191 .

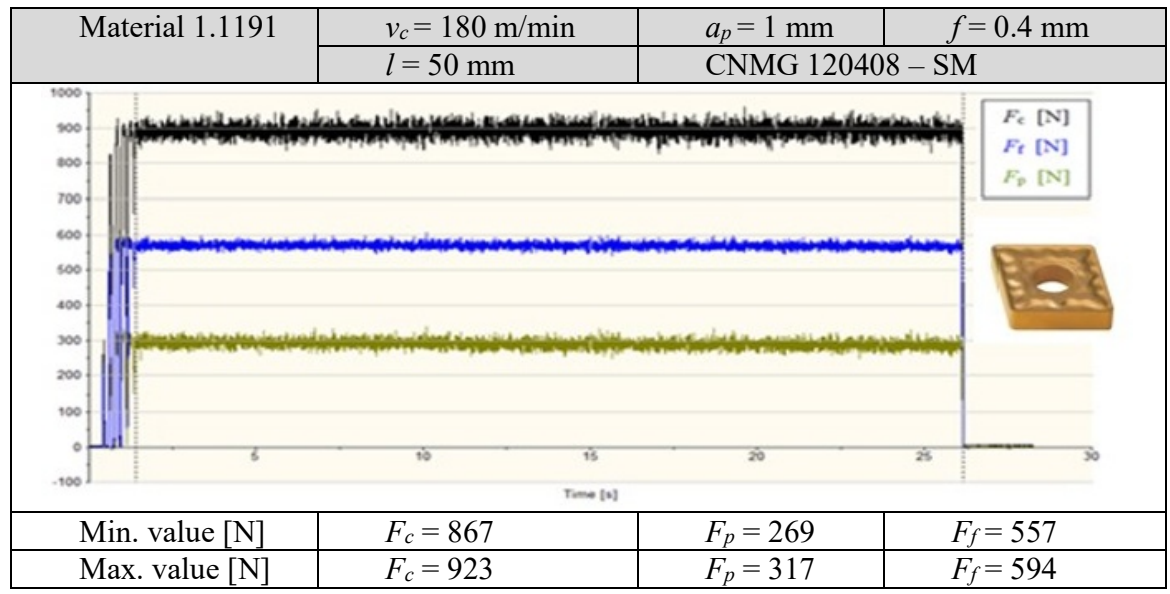

Fig. 1. Measured values of cutting forces components $F_{c}, F_{f}, F_{p}$ for material 1.1191

Based on the measured values of the cutting components $F_{c}, F_{f}, F_{p}$, the resulting force was calculated for turning both materials with both cutting inserts. Determination of resulting 
cutting force was preceded by statistical processing of the measured values. To determine the expanded uncertainty, the enlargement coefficient $k U=2$ with $95.5 \%$ coverage probability was used. Table 2 lists the processed values for material 1.1191.

Table 2. Measured values of cutting forces components $F_{c}, F_{f}, F_{p}$ for material 1.1191

\begin{tabular}{|c|c|c|c|}
\hline Material 1.1191 & $v_{c}=180 \mathrm{~m} / \mathrm{min}$ & $a_{p}=1 \mathrm{~mm}$ & $f=0.4 \mathrm{~mm}$ \\
\hline CNMG 120408-SM & $F_{c}=(892.5 \pm 5.4) \mathrm{N}$ & $F_{p}=(284.7 \pm 3.2) \mathrm{N}$ & $F_{f}=(570 \pm 2.2) \mathrm{N}$ \\
\hline \multicolumn{5}{|c|}{$F=(1096.5 \pm 4.6) \mathrm{N}$} \\
\hline Material 1.1191 & $v_{c}=180 \mathrm{~m} / \mathrm{min}$ & $a_{p}=2 \mathrm{~mm}$ & $f=0.2 \mathrm{~mm}$ \\
\hline CNMG 120408 $-\mathrm{SM}$ & $F_{c}=(963.4 \pm 5.4) \mathrm{N}$ & $F_{p}=(219.1 \pm 2.1) \mathrm{N}$ & $F_{f}=(679.1 \pm 2.4) \mathrm{N}$ \\
\hline \multicolumn{4}{|c|}{$F=(1198.9 \pm 4.6) \mathrm{N}$} \\
\hline Material 1.1191 & $v_{c}=180 \mathrm{~m} / \mathrm{min}$ & $a_{p}=1 \mathrm{~mm}$ & $f=0.4 \mathrm{~mm}$ \\
\hline CNMX 1204A2 $-\mathrm{SM}$ & $F_{c}=(796 \pm 5.4) \mathrm{N}$ & $F_{p}=(396.4 \pm 5.9) \mathrm{N}$ & $F_{f}=(491 \pm 3.1) \mathrm{N}$ \\
\hline \multicolumn{5}{|c|}{$F=(1015.8 \pm 5) \mathrm{N}$} \\
\hline Material 1.1191 & $v_{c}=180 \mathrm{~m} / \mathrm{min}$ & $a_{p}=2 \mathrm{~mm}$ & $f=0.2 \mathrm{~mm}$ \\
\hline CNMX 1204A2 $-\mathrm{SM}$ & $F_{c}=(907 \pm 3.7) \mathrm{N}$ & $F_{p}=(403.5 \pm 4.1) \mathrm{N}$ & $F_{f}=(576.9 \pm 2.9) \mathrm{N}$ \\
\hline \multicolumn{5}{|c|}{$F=(1148.2 \pm 3.4) \mathrm{N}$} \\
\hline
\end{tabular}

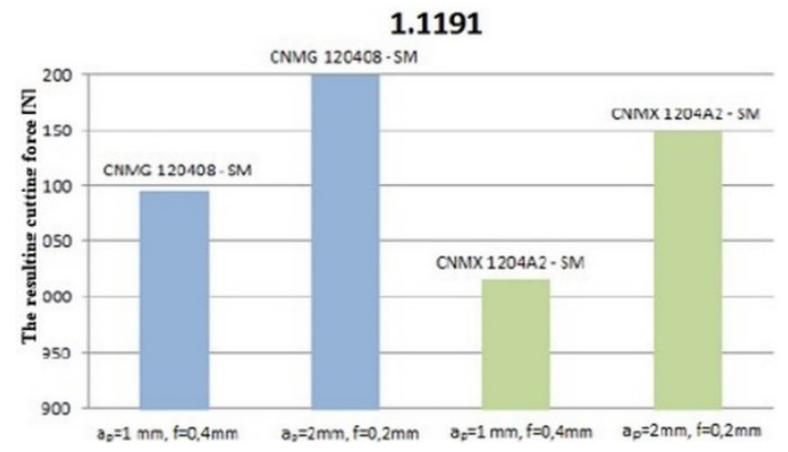

Fig. 2. The resulting cutting force for material 1.1191

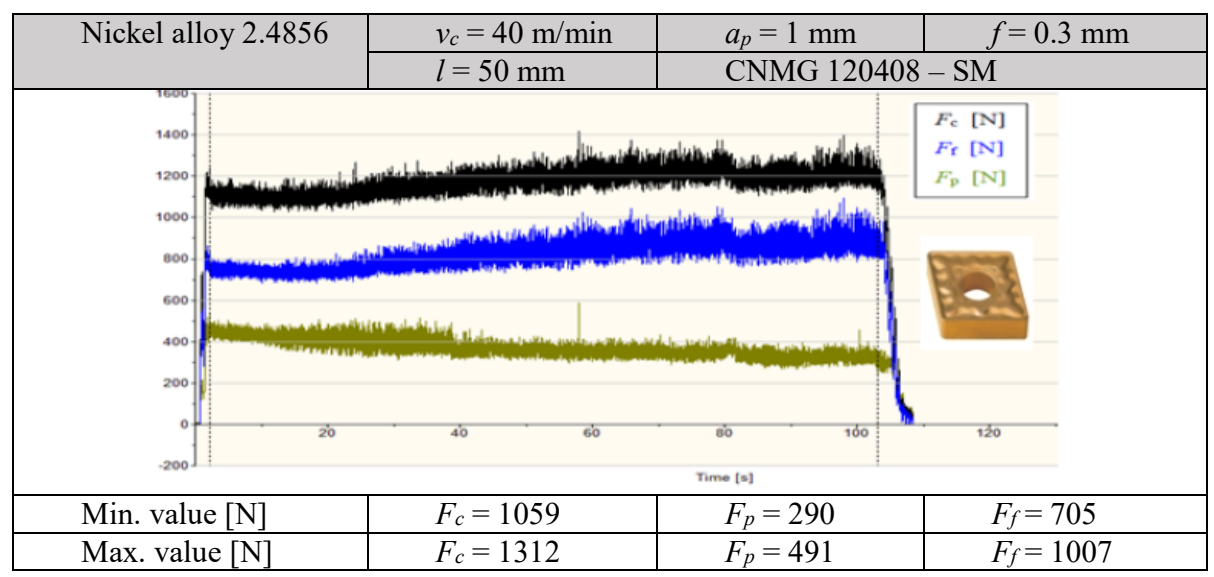

Fig. 3. Measured values of cutting forces components $F_{c}, F_{f}, F_{p}$ for material 2.4856 
Table 3. Measured values of cutting forces components $F_{c}, F_{f}, F_{p}$ for material nickel alloy 2.4856

\begin{tabular}{|c|l|l|l|}
\hline Nickel alloy 2.4856 & $v_{c}=40 \mathrm{~m} / \mathrm{min}$ & $a_{p}=1 \mathrm{~mm}$ & $f=0.3 \mathrm{~mm}$ \\
\hline CNMG 120408 $-\mathrm{SM}$ & $F_{c}=(1174.4 \pm 32.6) \mathrm{N}$ & $F_{p}=(369.6 \pm 24.4) \mathrm{N}$ & $F_{f}=(823.9 \pm 38.8) \mathrm{N}$ \\
\hline \multicolumn{5}{|c|}{$F=(1481.4 \pm 34.2) \mathrm{N}$} \\
\hline Nickel alloy 2.4856 & $v_{c}=40 \mathrm{~m} / \mathrm{min}$ & $a_{p}=2 \mathrm{~mm}$ & $f=0.15 \mathrm{~mm}$ \\
\hline CNMG 120408 $-\mathrm{SM}$ & $F_{c}=(1085.4 \pm 15.4) \mathrm{N}$ & $F_{p}=(283.4 \pm 3.5) \mathrm{N}$ & $F_{f}=(813.6 \pm 14.8) \mathrm{N}$ \\
\hline \multicolumn{4}{|c|}{$F=(1385.8 \pm 14.9) \mathrm{N}$} \\
\hline Nickel alloy 2.4856 & $v_{c}=40 \mathrm{~m} / \mathrm{min}$ & $a_{p}=1 \mathrm{~mm}$ & $f=0.3 \mathrm{~mm}$ \\
\hline CNMX 1204A2 $-\mathrm{SM}$ & $F_{c}=(1108.3 \pm 34.4) \mathrm{N}$ & $F_{p}=(631.5 \pm 55.5) \mathrm{N}$ & $F_{f}=(720 \pm 35.9) \mathrm{N}$ \\
\hline \multicolumn{5}{|c|}{$F=(1464.7 \pm 39.5) \mathrm{N}$} & $f=0.15 \mathrm{~mm}$ \\
\hline Nickel alloy 2.4856 & $v_{c}=40 \mathrm{~m} / \mathrm{min}$ & $a_{p}=2 \mathrm{~mm}$ & $F_{f}=(746.1 \pm 10.5) \mathrm{N}$ \\
\hline CNMX 1204A2 $-\mathrm{SM}$ & $F_{c}=(1106.8 \pm 10.3) \mathrm{N}$ & $F_{p}=(584.3 \pm 12.8) \mathrm{N}$ \\
\hline \multicolumn{5}{|c|}{$F=(1454.5 \pm 10.8) \mathrm{N}$} \\
\hline
\end{tabular}

\subsection{6}

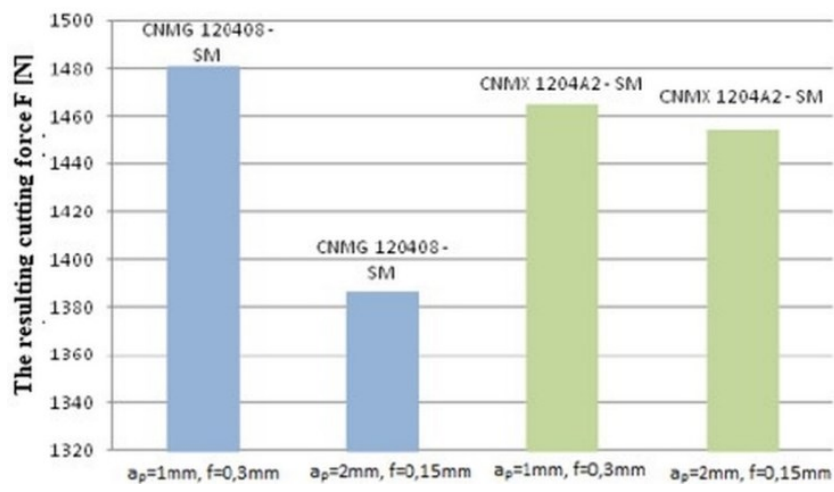

Fig. 4. The resulting cutting force for material 2.4856

From the above graphs it is possible to calculate the specific cutting resistance from:

$$
k_{c}=\frac{F_{c}}{A_{D}}[M P a]
$$

where: $k_{c}$ - cutting resistance [MPa], $F_{c}$-total cutting force [N], $a_{D}$ - width of cutting [mm].

Table 4. Values of cutting resistances for material 1.1191

\begin{tabular}{|c|l|l|c|}
\hline Material 1.1191 & $v_{c}=180 \mathrm{~m} / \mathrm{min}$ & \multicolumn{1}{|l|}{$a_{p}=1 \mathrm{~mm}$} & $f=0.4 \mathrm{~mm}$ \\
\hline CNMG 120408-SM & \multicolumn{3}{|c|}{$k_{c}=2231.3 \mathrm{MPa}$} \\
\hline Material 1.1191 & $v_{c}=180 \mathrm{~m} / \mathrm{min}$ & $a_{p}=2 \mathrm{~mm}$ & $f=0.2 \mathrm{~mm}$ \\
\hline CNMG 120408-SM & \multicolumn{3}{|c|}{$k_{c}=2408.5 \mathrm{MPa}$} \\
\hline Material 1.1191 & $v_{c}=180 \mathrm{~m} / \mathrm{min}$ & $a_{p}=1 \mathrm{~mm}$ & $f=0.4 \mathrm{~mm}$ \\
\hline CNMX 1204A2 -SM & & $k_{c}=1990 \mathrm{MPa}$ \\
\hline Material 1.1191 & $v_{c}=180 \mathrm{~m} / \mathrm{min}$ & $a_{p}=2 \mathrm{~mm}$ & $f=0.2 \mathrm{~mm}$ \\
\hline CNMX 1204A2 $-\mathrm{SM}$ & \multicolumn{3}{|c}{$k_{c}=2267.5 \mathrm{MPa}$} \\
\hline
\end{tabular}


Steel 1.1191

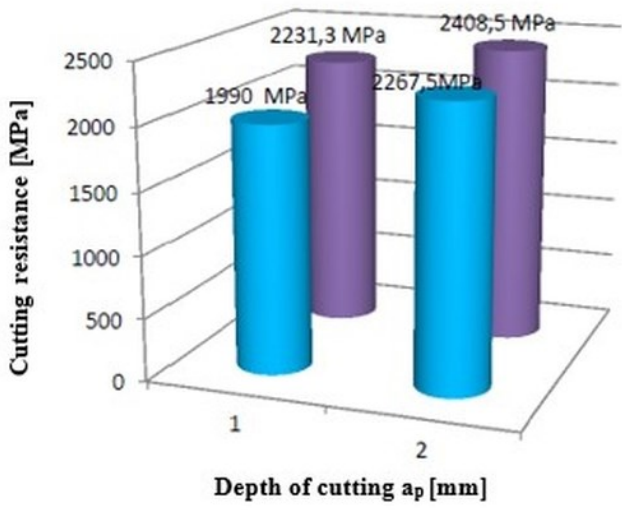

$\mathrm{kc}(\mathrm{CNMX} 1204 \mathrm{~A} 2-\mathrm{SM})$

ac (CNMG 120408 - SM)

Fig. 5. Cutting resistance for material 1.1191

Fig. 5 shows the dependence of the specific cutting resistance on the cutting conditions of the steel 1.1191. The highest value of the specific cutting resistance was machined by the CNMG $120408-$ SM cutting insert, cutting speed $v_{c}=180 \mathrm{~m} / \mathrm{min}$, feed rate $f=0.2 \mathrm{~mm}$ and depth of cut $a_{p}=2 \mathrm{~mm}$.

Table 5. Values of cutting resistances for material 2.4856

\begin{tabular}{|c|c|c|c|}
\hline Nickel alloy 2.4856 & $v_{c}=40 \mathrm{~m} / \mathrm{min}$ & $a_{p}=1 \mathrm{~mm}$ & $f=0.3 \mathrm{~mm}$ \\
\hline CNMG $120408-$ SM & \multicolumn{3}{|c|}{$k_{c}=3914.7 \mathrm{MPa}$} \\
\hline Nickel alloy 2.4856 & $v_{c}=40 \mathrm{~m} / \mathrm{min}$ & $a_{p}=2 \mathrm{~mm}$ & $f=0.15 \mathrm{~mm}$ \\
\hline CNMG 120408 - SM & \multicolumn{3}{|c|}{$k_{c}=3618 \mathrm{MPa}$} \\
\hline Nickel alloy 2.4856 & $v_{c}=40 \mathrm{~m} / \mathrm{min}$ & $a_{p}=1 \mathrm{~mm}$ & $f=0.3 \mathrm{~mm}$ \\
\hline CNMX 1204A2 - SM & \multicolumn{3}{|c|}{$k_{c}=3694.3 \mathrm{MPa}$} \\
\hline Nickel alloy 2.4856 & $v_{c}=40 \mathrm{~m} / \mathrm{min}$ & $a_{p}=2 \mathrm{~mm}$ & $f=0.15 \mathrm{~mm}$ \\
\hline CNMX 1204A2 - SM & \multicolumn{3}{|c|}{$k_{c}=3689.3 \mathrm{MPa}$} \\
\hline
\end{tabular}

Nickel alloy 2.4856

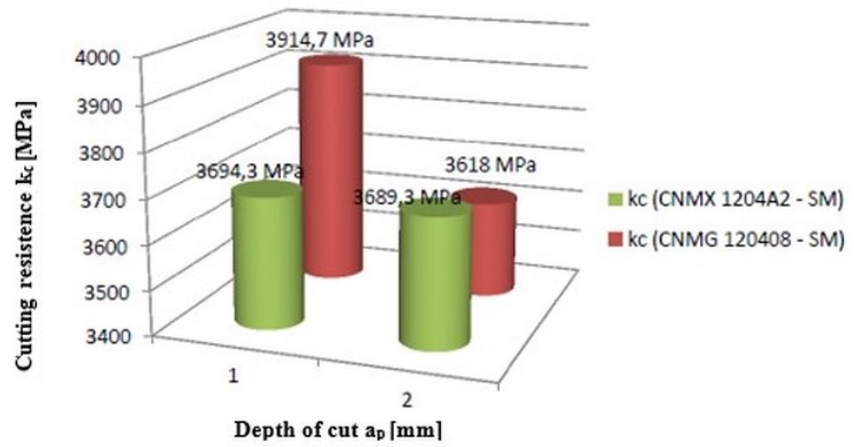

Fig. 6. Cutting resistance for material 2.4856

Fig. 6 shows the dependence of the specific cutting resistance on the cutting conditions during machining the material 2.4856. The graph shows a significant difference in the specific cutting resistance of CNMG 120408 - SM cutting inserts under the different cutting 
conditions. Using the cutting speed $v_{c}=40 \mathrm{~m} / \mathrm{min}$, feed $f=0.3 \mathrm{~mm}$ and depth of cut $a_{p}=1 \mathrm{~mm}$, the resulting value of the specific cutting resistance is $3914.7 \mathrm{MPa}$. When machining with the same replaceable cutting insert with different cutting conditions, the specific cutting resistance dropped to $300 \mathrm{MPa}$. The decrease in the specific cutting resistance mainly affected the feed rate, but also the depth of cut.

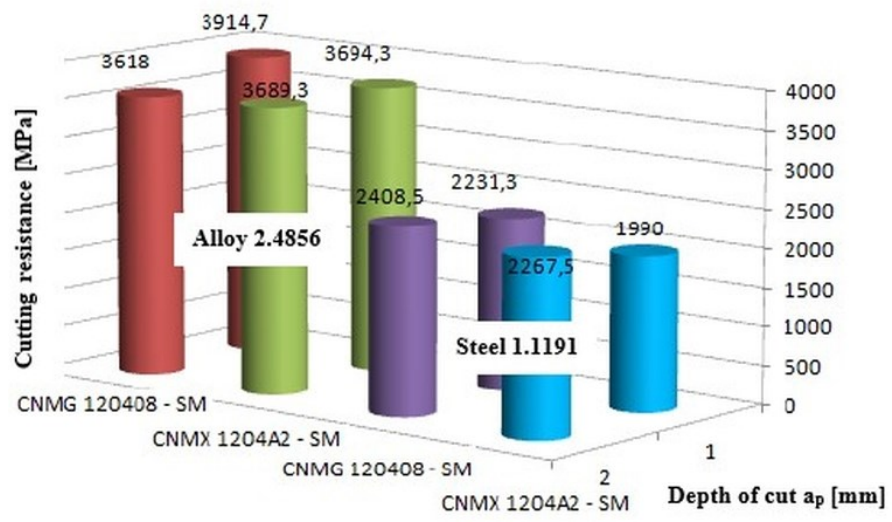

Fig. 7. Comparison of cutting resistance for materials 1.1191 and 2.4856

In the figure above, it can be seen that the machining of the 2.4856 nickel alloy is the value of the specific cutting resistors significantly higher. High machining values are due to the mechanical and physical properties of the alloy. For cutting nickel alloys with cutting speed $v_{c}=40 \mathrm{~m} / \mathrm{min}$, feed $f=0.3 \mathrm{~mm}$ and cutting depth $a_{p}=1 \mathrm{~mm}$, the values of specific cutting resistors are higher than cutting speed $v_{c}=40 \mathrm{~m} / \mathrm{min}, f=0.3 \mathrm{~mm}$ and the depth of cut $a_{p}=2 \mathrm{~mm}$. Steel 1.1191 behaves opposite, cutting speed $v_{c}=180 \mathrm{~m} / \mathrm{min}$, feed rate $f=0.4 \mathrm{~mm}$ and cutting depth $a_{p}=1 \mathrm{~mm}$ are values of specific cutting resistors lower than cutting conditions $v_{c}=180 \mathrm{~m} / \mathrm{min}, f=0.3 \mathrm{~mm}, a_{p}=2 \mathrm{~mm}$. The size of the specific cutting resistance is given by the material type, the cutting speed $v_{c}$, the feed rate $f$, the depth of cut, the geometry and the type of the tool.

\section{Conclusion}

The article was focused on the cross sectional area of the cut layer of material and its influence on the specific cutting resistance during turning of steel 1.1191 and alloy 2.4856. The cutting forces were measured during the machining process and the subsequent evaluation of the measured data. Two interchangeable inserts CNMG 120408 - SM and CNMX 1204A2 - SM were used for machining. For each interchangeable cutting insert, two types of cutting conditions were chosen so that for each material the roughly the same crosssectional area of the chip was used under different cutting conditions. Measurement was carried out using a three-part dynamometer.

Measured values of the components of the cutting forces were evaluated using graphs in which filtration was used to filter off high bursts. The filtered values were statistically processed and the resulting cutting forces were calculated for each interchangeable cutting plate under the given cutting conditions. Further, the calculation of the specific cutting resistance was performed.

From the result of the experiment, it can be seen that the value of the specific cutting resistor was considerably higher than that of the 1.1191 steel for the nickel alloy 2.4856. This difference is due to the physical and mechanical properties of these materials. When 
machining the material 2.4856 CNMG 120408 - SM and the cutting conditions that were the following, cutting speed $v_{c}=40 \mathrm{~m} / \mathrm{min}$, feed rate $f=0.3 \mathrm{~mm}$ and cutting depth $a_{p}=1 \mathrm{~mm}$, the value of the specific cutting resistance was higher than cutting speed $v_{c}=40 \mathrm{~m} / \mathrm{min}$, feed $f=0.15 \mathrm{~mm}$ and cutting depth $a_{p}=2 \mathrm{~mm}$. When working with the CNMX 1204A2 - SM exchangeable insert, the values of the specific cutting resistors were slightly different. For cutting 2.4856 steel, cutting speeds $v_{c}=180 \mathrm{~m} / \mathrm{min}$, displacement $f=0.4 \mathrm{~mm}$ and cutting depth $a_{p}=1 \mathrm{~mm}$, the values of the specific cutting resistors were lower than in cutting conditions where the cutting conditions the cutting speed $v_{c}=180 \mathrm{~m} / \mathrm{min}$, the feed rate $f=0.2 \mathrm{~mm}$ and the depth of cut $a_{p}=2 \mathrm{~mm}$. From these measured results it can be concluded that the specific cutting resistance depends on the material properties, the cutting conditions, but also on the geometry and the type of the tool.

Article has been done in connection with projects Education system for personal resource of development and research in field of modern trend of surface engineering - surface integrity, reg. no. CZ.1.07/2.3.00/20.0037 financed by Structural Founds of Europe Union and from the means of state budget of the Czech Republic and by project Students Grant Competition SP2018/150 and SP2018/136 financed by the Ministry of Education, Youth and Sports and Faculty of Mechanical Engineering VŠBTUO.

\section{References}

1. K.Vasilko, Technológia dokončovania povrchov. Prešov, Slovenská republika: Technická univerzita v Košiciach, Fakulta výrobných technológií so sídlom v Prešove 124 (1), 115 (2004), ISBN 808073

2. T. Zlámal, Přrispěvek k obrábění Ni superslitiny a hodnocení řezivosti vybraných řezných materiálù. Ostrava, 108 s. Disertační práce. VŠB - Technická univerzita Ostrava. Školitel: doc. Ing. Robert ČEP, Ph.D, (2015)

3. N. Grossi, Accurate and fast measurement of specific cutting force coefficients changing with spindle speed. Inter-national Journal of Precision Engineering and Manufacturing 18 (8), 1173-1180 (2017)

4. C. Yao, Z. Zhou, J. Zhang, D. Wu, L. Tan, Experimental study on cutting force of faceturning Inconel718 with ceramic tools and carbide tools, Advances in Mechanical Engineering 9 (7), 1-9 (2017)

5. E. Turkes, S. Orak, S. Neseli, M. Sahin, S. Selvi, Modelling of dynamic cutting force coefficients and chatter stability dependent on shear angle oscillation. International Journal of Advanced Manufacturing Technology 91 (1-4), 679-686 (2017)

6. E. Brinksmeier, W. Preuss, O. Riemer, R. Rentsch, Cutting forces, Tool wear and surface finish in high speed diamond machining. Precision Engineering 49, 293-304 (2017)

7. J. Zajac, J. Jurko, R. Čep, Top trendy v obrabani, II cast - Nastrojove materialy. Zilina: Media/St, s.r.o. Zilina, 193 (2006), ISBN 80-968954-2-7

8. M. Neslušan, Experimentálne metódy v trieskovom obrábaní. 1. vyd. Žilina: Žilinská univerzita v Žiline, 349 (2007), ISBN 978-80-8070-711-8

9. J. Petrů, T. Zlámal, R. Čep, M. Pagáč, M. Grepl, Influence of Strengthening Effect on Machinability of the Welded Inconel 625 and of the Wrought Inconel 625. In IMETI 2013 Procedings of the 6th International Multi-Conference on Engineering and Technological Innovation, USA, Florida, Orlando, 9th - 12th July 2013. Orlando : International Institute of Informatics and Systematics, 1st edition + proceedings on CD, $1-5(2013)$ 
10. M. Neslušan, A. Czán, Obrabanie titanovych a niklovych zliatin. Zilina: Zilinska univerzita v Ziline / EDIS, 189 (2001), ISBN 80-7100-933-4

11. D. Stančeková, M. Drbúl, M. Janota, N. Náprstková, A. Kulla, J. Mrazik, Influence of manufacturing parameters on final quality of lapped parts. Manufacturing Technology 16 (1), 253-259 (2016)

12. A. Humár, TECHNOLOGIE I: Technologie obráběni - 1.část [online]. [cit. 2016-0210]. Available from: http://ust.fme.vutbr.cz/obrabeni/opory-save/TI_TO-1cast.pdf

13. G. M. Krolczyk, P. Neislony, S. Legutko, Determination of tool life and research wear during duplex stainless steel turning, Archives of Civil and Mechanical Engineering 15 (2), 347 - 354 (2015) 